This item was submitted to Loughborough's Research Repository by the author.

Items in Figshare are protected by copyright, with all rights reserved, unless otherwise indicated.

\title{
Improving the chest protection of elderly occupants in frontal crashes using SMART load limiters
}

PLEASE CITE THE PUBLISHED VERSION

http://dx.doi.org/10.1080/15389588.2015.1064528

PUBLISHER

(c) Taylor \& Francis

\section{VERSION}

AM (Accepted Manuscript)

\section{PUBLISHER STATEMENT}

This work is made available according to the conditions of the Creative Commons Attribution-NonCommercialNoDerivatives 4.0 International (CC BY-NC-ND 4.0) licence. Full details of this licence are available at: https://creativecommons.org/licenses/by-nc-nd/4.0/

\section{LICENCE}

CC BY-NC-ND 4.0

\section{REPOSITORY RECORD}

Ekambaram, Karthikeyan, Richard Frampton, and Lisa Jackson. 2015. "Improving the Chest Protection of Elderly Occupants in Frontal Crashes Using SMART Load Limiters". Loughborough University. https://hdl.handle.net/2134/18982. 


\section{Improving the Chest Protection of Elderly Occupants in Frontal Crashes using SMART Load Limiters}

Karthikeyan Ekambaram, Richard Frampton, Lisa Bartlett

Loughborough University, UK

Correspondence: Karthikeyan Ekambaram, Design School, Loughborough University, Loughborough, Leicestershire, LE11 3TU, UK

Email Address: k.ekambaram@lboro.ac.uk

\section{ABSTRACT}

Objective: To determine whether varying the seat belt load limiter (SBL) according to crash and occupant characteristics could have real world injury reduction benefits in frontal impacts and if so, to quantify those benefits.

Methods: Real world UK accident data were used to identify the target population of vehicle occupants and frontal crash scenarios where improved chest protection could be most beneficial. Generic baseline driver and front passenger numerical models using a $50^{\text {th }}$ percentile dummy were developed with MADYMO software. Simulations were performed where the load limiter threshold was varied in selected frontal impact scenarios. For each SBL setting, restraint performance, dummy kinematics and injury outcome were studied in five different frontal impact types. Thoracic injury predictions were converted into injury probability values using AIS 2+ age dependent thoracic risk curves which were developed and validated based on a methodology proposed by Laituri et al. (2005). Real world benefit was quantified using the predicted AIS 2+ risk and assuming an appropriate adaptive system was fitted to all the cars in a real world sample of recent frontal crashes involving European passenger cars.

Results: From the accident data sample the chest was the most frequently injured body region at an AIS 2+ level in frontal impacts (7\% of front seat occupants). The proportion of older vehicle front seat occupants (>64 years) with AIS 2+ injury was also greater than the proportion of younger occupants. Additionally, older occupants were more likely to sustain seat belt induced serious chest injury in low and moderate speed frontal crashes. In both front seating positions, the low SBL provided the best chest injury protection, without increasing the risk to other body regions. In severe impacts, the low SBL allowed the driver to move dangerously close to the steering wheel. Compared to the driver side, greater ride down space on the passenger side gave a higher potential for using the low SBL's. When applying the AIS 2+ risk reduction findings to the weighted accident data sample, the risk of sustaining an AIS $2+$ seat belt injury changed to $0.9 \%, 4.9 \%$ and $8.1 \%$ for young, mid and older occupants respectively from their actual injury risk of $1.3 \%, 7.6 \%$ and $13.1 \%$.

Conclusions: These results suggest the potential for improving the safety of older occupants with the development of smarter restraint systems. This is an important finding since the number of older users is expected to increase rapidly over the next 20 years. The greatest benefits were seen at lower crash severities. This is also important since most real world crashes occur at lower speeds.

Keywords: Accident data, Frontal impacts, Smart restraints, Chest injury, Older occupants, Benefit analysis 


\section{INTRODUCTION}

Introduction of the European frontal impact directive (UNECE R94) and EuroNCAP test has significantly improved occupant protection in frontal impact through advancements in vehicle structure and restraint systems. Frontal airbags and three-point seat belt systems with load limiters and pretensioners form an integral part of modern restraints. In the regulatory crash test, the car strikes a 40\% offset deformable barrier head-on at 56 $\mathrm{km} / \mathrm{h}$. The crash performance of the vehicle is assessed by comparing the crash dummy loads with the prescribed limits. The EuroNCAP test is similar to the regulatory test, but is conducted at a higher impact speed (64 km/h). Offset test requirements have generally reduced occupant compartment intrusion through an increase in the stiffness of frontal crash structures and occupant compartment strength.

The senior population is growing rapidly across the globe. In Europe, the ratio of the number of people aged over 65 years to the population aged 15-64 years is projected to double between 2010 and 2050 (Lanzieri 2011). It is a well-documented fact that, in general, senior vehicle occupants are more vulnerable to injury in a crash and they tend to have worse outcomes for a similar level of injury (Kent et al. 2009). Kent and his colleagues (Kent, Henary, et al. 2005) analysed the NASS CDS raw data between 1992 and 2002 and found that as many as half of older drivers had sustained fatal injuries that would result in survival if sustained by younger drivers. The higher rate of chest injury and associated mortality to elderly occupants is reported by several authors (Morris et al. 2003; Frampton and Lenard 2009; Hill et al. 1994; Welsh et al. 2006). Skeletal fractures are the most common type of serious chest injury in frontal impacts and elderly occupants are increasingly susceptible to skeletal injuries from seat belt loading (Morris et al. 2003; Welsh et al. 2006). Changes in the geometrical and material characteristics of the rib structures with ageing reduce the ability to withstand trauma, resulting in increased thoracic skeletal injury (Kent, Lee, et al. 2005; Laituri et al. 2005; Gayzik et al. 2008; Cowin 2001). Analysing the U.S. National Trauma Databank, Kent et al. (2008) found that occupants aged above 60 years had increased fatality risk from rib fractures. In fact, the majority of elderly occupants who died of a chest trauma had no injury worse than rib fractures. These predictions emphasise the need to improve the protection offered by current restraint systems for senior vehicle users involved in a crash.

In Europe the deployment characteristics of restraint systems are generally optimised to best protect an average young male, using a mid- sized male crash dummy (stature $=175 \mathrm{~cm}, \mathrm{BMI}=24.3 \mathrm{~kg} / \mathrm{m} 3$ ) in a EuroNCAP frontal crash test. Most modern restraint systems remain "Single Point” i.e. they will deploy at a certain pre-determined value (usually an acceleration level according to a deployment algorithm in the restraint control module, or a specific belt load), although some manufacturers claim that some variation in the population is catered for. Optimising safety systems to one particular type of crash test and one particular type of occupant has produced safety gains but these systems may not provide similar levels of effectiveness when the crash conditions vary with respect to the regulatory compliance test procedure. Therefore, there is a need to consider crash protection potential for a wider occupant group, especially for older occupants whose numbers are increasing rapidly.

Smart restraint technology is a possible way to achieve the deployment variability. One way to increase the capability of the belt restraint would be to adapt the load limiter threshold according to crash needs. Mertz and Dalmotas (2007) demonstrated the principle that lowering shoulder belt force can provide gains in chest injury 
risk reduction. The challenge going forward is to know when and how to vary the load limiter in real crashes in order to achieve the best chest injury reduction without compromising the protection to other body regions.

The objectives of the current work are therefore a) to define the type of occupant and frontal crash associated with chest injury from the seat belt, b) to study the effect on injury outcome of varying the load limiter threshold in different frontal crash types using numerical simulation, and c) to apply the results to real world accident data to estimate the potential injury reduction benefits.

\section{METHODS}

\section{Accident Data Sample}

Real world accident data were examined to identify the target population of vehicle occupants and frontal crash scenarios where improved chest protection could be most beneficial. The UK Co-operative Crash Injury Study (CCIS) data collected between 1998 and 2008 were used. CCIS collected in-depth crash and injury information from selected geographical regions representing urban and rural roads in Great Britain (Mackay et al. 1985; Hassan et al.1995). An accident was included in the sample if it a) occurred in one of the specified sample regions, b) at least one occupant of a passenger car (7 years old or less at the time of the crash) was injured according to the police assessment and c) the vehicle was towed from the accident scene. The study investigated some 80 per cent of 'serious' and 'fatal' and 10-15 per cent of 'slight' injury crashes in the sample regions. Consequently, the slight injury records were under-represented in the data which was biased toward more serious crashes. Weighting factors based on sampling percentage were applied to the data in order to give a representative population of crashes. The injury outcome was recorded using the Abbreviated Injury Scale (AAAM 1990). The crash severity in this study was determined by the Equivalent Test Speed (ETS). ETS is the vehicle delta $\mathrm{v}$, calculated on the assumption that deformation was caused by impact with a fixed rigid barrier (Lenard et al. 1998). The criteria used to select the frontal impact population are shown below:

- $\quad$ Single frontal impact or two impacts with frontal impact being the most significant in causing injuries

- $\quad$ No under-ride

- Non rollover crashes

- $\quad$ Principal direction of force (DOF) between 11 and 1 o’ clock

- Vehicles manufactured after the calendar year 1995

- Three point belted front seat occupants $>=15$ years of age

- Vehicle with frontal airbag, and seatbelt pretensioner

\section{Numerical Simulations}

Model development: Generic baseline driver and front passenger compartment models using MADYMO V7.4.1 were developed with identical frontal restraints and interiors including the steering system, seat and front fascia (dashboard) (TNO 2013). The models were representative of a C segment car, also termed Small Family Car in Europe. This approximates to the Compact Car category in North America. An example of a car in this segment is the Volkswagen Golf. The $\mathrm{C}$ segment vehicle is one of the most popular in Europe. The models represented the front compartment of a passenger car and the important points of front seat occupant 
interaction in a frontal impact (Appendix 1). The stiffness characteristics of the vehicle interior components such as the steering column, front fascia and seats were based on those defined for the TNO frontal application model (TNO 2013). The windscreen, floor and toe pan were considered to be rigid. In both models, the MADYMO $50^{\text {th }}$ percentile Hybrid III ellipsoidal male dummy was positioned as in EuroNCAP frontal crash tests.

The compartment models were developed with an initial baseline restraint system. This consisted of a frontal airbag and a 3-point belt with retractor, buckle pretensioner and load limiting at the shoulder. The modelled retractor was located at the shoulder belt lower anchorage and was locked at $1 \mathrm{~ms}$ in to each simulated impact. The pretensioner was modelled with a translational joint in parallel with a spring and was located at the belt buckle. When triggered, this exerted a maximum force of $1.5 \mathrm{kN}$ on the belt and was able to recoil up to $100 \mathrm{~mm}$ of belt slack. A $4 \mathrm{kN}$ load limiter was represented in the baseline models. The driver airbag was adapted from the TNO frontal application model. It was a standard folded circular airbag with a volume of approximately 43 litres. The passenger compartment had a generic frontal airbag with a volume of approximately 120 litres. Both airbags were positioned to provide an adequate representation of dummy interaction with the airbag while deployed. The gas outflow from the airbag was controlled by the vent holes and the fabric permeability. It was assumed that vehicle intrusion was negligible in all simulated impacts.

The developed models were validated in two stages. Firstly, the attributes such as dummy orientation (pelvis angle), position of dummy with respect to vehicle interiors (e.g., chest to steering hub distance, nose to steering rim distance, abdomen to steering rim distance), and the orientation of the vehicle components (e.g., angle of steering wheel and steering column angle) were compared against measurements obtained from the USNCAP frontal barrier test reports of vehicles classified as a small family car according to EuroNCAP. The model details and its comparison with the measurements of the real car samples are detailed in Appendix 2. Secondly, the baseline predictions for head, chest and pelvic acceleration were compared against measures obtained in comparable tests using the validated PRISM project (Bosch-Rekveldt et al. 2005) numerical model. For validation, the EuroNCAP impact pulse from a full-scale crash test of an equivalent size vehicle was applied in both numerical models. Trends in acceleration were similar although differences were observed in the timing and peak measures predicted by both models (Appendix 3). These were mainly due to modelling differences in occupant seat position and airbag size. Nevertheless, the overall magnitude of the baseline predictions were comparable and below the thresholds specified in the European frontal impact directive.

Test definition: Worldwide, NCAP frontal tests generally emphasise restraint performance in a full overlap high crash pulse scenario (56 km/h USNCAP) or vehicle structural performance in a high speed offset impact configuration (64 km/h EuroNCAP). The accident data analysis demonstrated that the majority (70\%) of front seat occupants with AIS 2+ chest injury from the seat belt were involved in frontal crashes between 20 and 45 $\mathrm{km} / \mathrm{h}$. Much lower impact severities than those employed in NCAP testing. Therefore, to cover as wide a range of real frontal crash conditions as possible, and based on availability of crash pulse data, five frontal crash scenarios were selected for modelling. These included both high and low crash severities. The pulses were based on front end overlap and test speed applied to a C segment passenger car. Using this selection, a series of 40 parametric tests were defined and simulated. The following crash pulse data were applied to the compartment 
models during the parametric investigations. Peak pulses are shown but it should be noted that pulse duration also differed between full and offset impact types:

1. Low pulse

- Low FRB: Full width rigid barrier impact at $26 \mathrm{~km} / \mathrm{h}$ (peak pulse $14 \mathrm{~g}$ )

- Low ODB: $40 \%$ offset deformable barrier impact at $40 \mathrm{~km} / \mathrm{h}$ (peak pulse $17 \mathrm{~g}$ )

2. Mid pulse

- $\quad$ Mid: $40 \%$ offset deformable barrier impact at $56 \mathrm{~km} / \mathrm{h}$ (peak pulse $30 \mathrm{~g}$ )

3. High pulse

- $\quad$ EuroNCAP: 40\% offset deformable barrier impact at $64 \mathrm{~km} / \mathrm{h}$ (peak pulse $33 \mathrm{~g}$ )

- $\quad$ USNCAP: Full width rigid barrier impact at $56 \mathrm{~km} / \mathrm{h}$ (peak pulse $40 \mathrm{~g}$ )

Passenger compartment intrusion was not considered in the numerical simulation based on two assumptions. Most European vehicles would exhibit minimal intrusion in the selected impact scenarios and intrusion would limit the scope for injury reduction using variable load limiters. The pretensioner was fired at 15ms in all selected impacts and the seat belt load limiting was varied between $2 \mathrm{kN}, 3 \mathrm{kN}$, and $6 \mathrm{kN}$ along with a baseline model of $4 \mathrm{kN}$. Airbag triggering time was set according to the crash severity and was as follows a) Low FRB : $45 \mathrm{~ms}$, b) Low ODB : $38 \mathrm{~ms}$, c) Mid : $28 \mathrm{~ms}$, d) EuroNCAP : $25 \mathrm{~ms}$ and e) USNCAP : $15 \mathrm{~ms}$. The analysis was conducted in both front seating positions.

Equivalent real world crashes: In order to assess the relevance of the model's chest injury predictability for real crashes, predicted chest injury risks were compared to those in equivalent real world impacts which were deliberately narrowed to closely resemble the simulations, both in terms of front end overlap and impact speed. Real world frontal crashes with overlap above 70\% were considered as full overlap (100\%) and crashes with overlap less than 60\% were considered as offset (40\%). Crashes with overlap between 60 and $70 \%$, front fascia and/or steering wheel intrusion above $80 \mathrm{~mm}$ and impact to narrow objects with diameter $<41 \mathrm{~cm}$ were excluded to improve the match.

1. Low pulse

- Low FRB: ETS 20 - $30 \mathrm{~km} / \mathrm{h}$, overlap $>70 \%$

- $\quad$ Low ODB: ETS 35 - $45 \mathrm{~km} / \mathrm{h}$, overlap $<60 \%$

2. Mid pulse

- Mid: ETS 51 - $60 \mathrm{~km} / \mathrm{h}$, overlap $<60 \%$

3. High pulse

- $\quad$ EuroNCAP: ETS 61 - 70 km/h, overlap <60\%

- USNCAP: ETS 51 - $61 \mathrm{~km} / \mathrm{h}$, overlap >70\%

\section{Selection of Best Load Limiter Setting}

Tuning the restraints to benefit one body region may have a negative effect on other body regions. To gauge the performance of the restraint system in a simulated crash scenario, a method used by NHTSA to determine the 
joint injury probability (Pjoint) was adopted. The evaluation combines the injury risk to each selected body region assuming that injury to different body regions are independent events (NHTSA 2008).

$$
P_{\text {joint }}=1-\left[\left(1-P_{\text {head }}\right)\left(1-P_{\text {neck }}\right)\left(1-P_{\text {chest }}\right)\left(1-P_{\text {femur }}\right)\right]
$$

The Phead, Pneck, Pchest and Pfemur are the injury probability of head, neck and chest sustaining AIS 3+ injury and the femur sustaining AIS 2+ injury (NHTSA 2008).

The presence of the steering wheel reduces the ride down space on the driver side. High dummy excursion generally increases the chances of hard contact with the vehicle interior and unstable contact with the deploying airbag. An additional measure was used to classify the excursion of the driver dummy as safe or not safe in each of the simulated crash scenarios since dynamic steering wheel intrusion was not considered. From the accident data it was found that $85 \%$ of the records with ETS between $40 \mathrm{~km} / \mathrm{h}$ and $70 \mathrm{~km} / \mathrm{h}$ had steering wheel displacement less than $80 \mathrm{~mm}$. Consequently, the best restraint system was selected in the driver tests only if (a) the chest injury was reduced without increasing the overall injury risk and b) the minimum distance between the dummy and steering wheel was greater than $80 \mathrm{~mm}$.

\section{Benefit Quantification}

One of the research aims was to quantify the real world injury benefit of the smart restraint. It was achieved by applying the estimated chest injury risk reduction from the simulations to the accident target sample according to the occupant seating position, impact scenario and age. For this purpose, frontal impacts where front seat occupants had sustained AIS 2+ chest injury only from seat belt loading were matched to the simulated impacts. The inclusion and exclusion criteria used in the predictability analysis were employed, although crash speed bands were widened to retain as many cases as possible while still representing the general type of loading severity of the simulated impacts.

1. Low pulse

- Low FRB: ETS $\leq 40 \mathrm{~km} / \mathrm{h}$, overlap $>70 \%$

- Low ODB: ETS $\leq 45 \mathrm{~km} / \mathrm{h}$, overlap $<60 \%$

2. Mid pulse

- Mid: ETS 40 - 60 km/h, overlap <60\%

3. High pulse

- EuroNCAP: 61 -70 km/h, overlap $<60 \%$

- USNCAP: 41 - $70 \mathrm{~km} / \mathrm{h}$, overlap $>70 \%$

It was assumed that, in each of the categorised crash scenarios, the predicted chest injury risk of the baseline model would be representative of the real world chest injury risk, and by switching to the best SBL model, the real world injury risk would reduce relative to the corresponding simulated predictions. Thus, the overall frequency of AIS 2+ seat belt related chest injury after employing the smart restraint system was calculated using Eq. (2).

$$
F_{\text {smart }}=\sum_{i=1}^{2 \text { position }} \sum_{j=1}^{5 \text { impact }} \sum_{k=1}^{3 \text { age }}\left[F_{\text {actual }}\right]_{i j k} \frac{\left[R_{\text {best }}\right]_{i j k}}{\left[R_{\text {base }}\right]_{i j k}}
$$


where

- $\quad F_{\text {smart }}$ is the estimated frequency of occupants to sustain AIS 2+ chest injury with a smart system

- $\left[F_{\text {actual }}\right]_{i j k}$ is the actual frequency of AIS $2+$ chest injured in the sample for the particular seating position, impact condition and age group

$\left[R_{\text {best }}\right]_{i j k}$ and $\left[R_{\text {base }}\right]_{i j k}$ are the AIS $2+$ chest injury risk of best and baseline model respectively, estimated for the particular seating position, impact condition and age group

It was necessary to transfer the simulation results to the likely chest injury severity in terms of the AIS, recorded in the accident sample. Chest injury risk functions were used for this purpose. An AIS 3+ chest injury risk curve was developed by Laituri and his colleagues (Laituri et al. 2005) using a dataset containing post mortem human subjects (PMHS) test results. One of the requirements of the study reported in this paper was to estimate $\mathrm{F}_{\text {smart }}$ from Eq. (2) for AIS 2+ chest injury. Therefore, the methodology developed by Laituri et al. (2005) was applied to the same PMHS dataset, in order to develop an AIS 2+ chest injury risk curve.

AIS 2+ chest injury risk curve: As in the reference work (Laituri et al. 2005), the number of rib fractures (NRF) sustained by the PMHS was used to assess the injury severity outcome. The difference between skeletal injury outcome among live occupants and the PMHS was also considered. Viano et al. (1977) and Foret Bruno et al. (1978) observed cadaver specimens sustaining two or three more rib fractures than live humans.

Accordingly, if the PMHS in the database had sustained 4 or more rib fractures, then the injury level was coded as AIS 2+. Laituri et al. (2005) found logistic regression analyses using the modified maximum likelihood method (Nakahira et al. 2000) with normalised chest compression $(\overline{\mathrm{UC}})$ and age as the predictor variables, produced the best AIS 3+ injury risk function. A similar procedure was applied for the AIS 2+ injury risk calculation. MATLAB was used to compute the statistical calculation.

The resulting probability estimate of age dependant AIS 2+ chest injury, as a function of chest deformation for crash test dummies, is expressed below (Eq. (3)).

$$
P(\text { AIS } 2+)=\frac{1}{1+\operatorname{EXP}\left(12.432-0.0562 \text { Age }-1.7955(\text { ChestDefl })^{0.4612}\right)}
$$

The developed injury risk function was validated by comparing the theoretical risk and the actual field injury rates (Appendix 4). The details of the validation process can be found in Laituri et al. $(2005,2003)$.

\section{RESULTS}

\section{Accident Analysis}

The unweighted accident sample consisted of 2644 front seat occupants. Applying weighting factors gave 7729 front seat occupants consisting of 6644 (86\%) drivers and 1085 (14\%) front passengers. Unless otherwise stated, all further analyses used weighted data. Around $60 \%$ of the sample had load limiters, $20 \%$ had no load limiters and for the remaining $20 \%$, the presence of a load limiter was unknown. The load limiting threshold employed in each vehicle was not recorded in the accident data. Industry intelligence suggests that vehicles manufactured early in the sample might have employed load limiter thresholds as high as $6 \mathrm{kN}$, dropping to $4 \mathrm{kN}$ as structural 
performance was improved. The mean occupant age in the sample was 41 years. The driver sample contained 3571 occupants aged between 17 and 39 (young), 2358 aged 40-64 years (middle-aged) and 715 aged 65+ years (old). The passenger sample included 537 occupants aged between 15 and 39 years (young), 355 aged between 40 and 64 years (middle- aged) and 193 aged 65+ years (old).

In the overall weighted sample, 524 (7\%) of all front seat occupants had sustained AIS 2+ chest injury. The chest was the most frequently injured body region at the AIS 2+ injury level followed by the upper and lower extremities (6\% each). The chest injury risk varied among age groups, in the sample $2 \%$ of the younger occupant, $10 \%$ of the middle age occupants and $17 \%$ of the older occupants had sustained AIS $2+$ chest injuries. A Chi-square test confirmed that there were significant differences in the chest injury severity rates between age groups $(\mathrm{p}<0.001)$.

Around 90\% of occupants with AIS 2+ chest injuries experienced impact speeds lower than that of the current European regulatory test (56 km/h). The mean ETS of AIS 2+ chest injured older occupants (32 km/h) was less than that for younger $(45 \mathrm{~km} / \mathrm{h})$ and middle aged $(34 \mathrm{~km} / \mathrm{h})$ occupants.

377 (72\%) of front seat occupants sustained their AIS 2+ chest injuries from the seat belt alone. Injury causation for the remaining $28 \%$ was either from the vehicle interior or a combination of belt plus interior. The majority (68\%) of all serious injuries to chest regions were rib or sternum fractures. In frontal impacts, the seat belt plays a significant role in controlling chest load. Therefore, seat belt induced chest injuries are likely to be mitigated by adapting the load limiter according to the crash needs. Furthermore, a reduction in soft tissue injuries and associated intrathoracic organ injuries can also be expected with a reduction in skeletal injury.

\section{Numerical Simulations}

Four different load limiter settings were simulated in five impact scenarios for both front seating positions. In each of the simulated impacts, the shoulder belt forces, forward dummy excursion and dummy loads were analysed. In order to assess the predictability of the numerical model for AIS 2+ belt induced chest injury, simulation results using the baseline $4 \mathrm{kN}$ load limiter were compared to the real world AIS 2+ chest injury risk using chest deflection outcome. Chest injury risks for the mean age group of the sample were estimated using the developed injury risk function. The results comparing simulated and real risks are shown in Appendix 5. There was not a direct match between the simulated and real chest injury risks, although the order in which the predicted risk increased by simulated impact configuration was generally mirrored in the real crashes. The real world risk for the $64 \mathrm{~km} / \mathrm{h}, 40 \%$ offset impact was $0 \%$ but this may have been the result of only a handful of real cases (3) matching that crash configuration.

Driver model: The dummy acceleration and displacement was influenced by the crash pulse severity and load limiter behaviour. The belt load time history curves for all tested driver impacts are provided in Appendix 6. It can be observed that, for all load limiter values, the peak loads for both the low crash pulses were less than $4 \mathrm{kN}$ and the measured forces for the $4 \mathrm{kN}$ and $6 \mathrm{kN}$ load limiter were very similar. Only with the high pulses did the peak load of $6 \mathrm{kN}$ occur with the $6 \mathrm{kN}$ load limiter. 
The measured minimum distance between thorax and steering wheel and head and steering wheel are shown in Figure 1. The extra seat belt webbing with the SBL thresholds less than $4 \mathrm{kN}$ allowed the dummy to displace further towards the steering wheel than with the baseline $4 \mathrm{kN}$ SBL. The selected safe zone excursion limit of 80 $\mathrm{mm}$ is shown as dotted lines in Figure 1. It can be observed that the dummy head excursion was safe in all low pulse simulations. In high pulse impacts, the dummy tended to displace very close to the steering wheel with the $2 \mathrm{kN}$ SBL. The chest and head of the dummy did not bottom out through the airbag in any of the impacts.

Injury risk assessment values for the 2 and 4 kN SBL in all simulated impacts are listed in Table 1 whilst the results for all SBL thresholds are given in Appendix 8. In mid and high pulse impacts with a $2 \mathrm{kN}$ SBL, the greater forward displacement gave rise to unstable head contact on the airbag. This pushed the airbag forward and upward, reducing the amount of airbag between chest and wheel. In contrast to the low severity crash pulses, the peak chest accelerations with the $2 \mathrm{kN} \mathrm{SBL}$ in high pulse impacts were noticeably greater than with the $4 \mathrm{kN}$ SBL despite the chest deflection being lower with the $2 \mathrm{kN}$ SBL. This was likely due to the unstable loading of the airbag onto the steering wheel rim. Nevertheless, even a small extra forward displacement of the thorax could have induced much harder contact, resulting in increased chest deflection and acceleration. The $3 \mathrm{kN}$ SBL in the mid pulse impact produced lower chest deflection value whilst avoiding any unstable contact with the airbag. In all impacts, the HIC and chest deflection outcome exhibited a positive correlation with the SBL threshold. Due to high belt pay-out and subsequent interaction with the airbag, the neck extension outcome was significantly higher with the $2 \mathrm{kN}$ SBL in mid crash pulse and EuroNCAP impacts. The $2 \mathrm{kN}$ SBL (allowing a greater amount of forward displacement) resulted in higher femur loads. The increase in AIS 2+ injury risk did not however reach levels which would give rise to concern. For example, the femur axial force measured using a $2 \mathrm{kN}$ and $4 \mathrm{kN} \mathrm{SBL}$ with the low FRB pulse corresponds to $0.7 \%$ and $0.4 \%$ AIS $2+$ femur injury risk respectively.

Passenger model: The dummy did not have a hard contact with the vehicle interior in any of the simulated impacts. Using the $6 \mathrm{kN} \mathrm{SBL}$, the belt force reached $6 \mathrm{kN}$ only in the mid and high pulse impacts. In low pulse impacts, the resultant forces using the $4 \mathrm{kN}$ and $6 \mathrm{kN} \mathrm{SBL}$ were very similar (Appendix 7). Injury risk assessment values for the $2 \mathrm{kN}$ and $4 \mathrm{kN}$ SBL in all simulated impacts are shown in Table 2. The HIC outcomes were generally lowest using the $2 \mathrm{kN}$ SBL. The only exception being a lower HIC for the low FRB pulse when using the $4 \mathrm{kN} \mathrm{SBL}$. The $2 \mathrm{kN}$ SBL produced lowest chest compression scores in all impacts. But a greater forward displacement of the dummy in high pulse impacts with a $2 \mathrm{kN}$ SBL resulted in higher chest and head peak acceleration. More simulation runs with different adapted dummy postures and crash pulses would be required for a greater understanding of the effect of the $2 \mathrm{kN} \mathrm{SBL}$ in such crash scenarios. The $3 \mathrm{kN}$ SBL in mid pulse and EuroNCAP impacts provided the best injury protection with stable airbag loading (Appendix 8).

Chest injury risk: The risk of AIS 2+ chest injury in each impact scenario for different age groups, when employing baseline and best restraint systems are shown in Table 3. In impacts where a low SBL did not provide the best result, the load limiter threshold was set at the baseline value of $4 \mathrm{kN}$. In the AIS 2+ chest injury risk function, the age was set as 30, 50 and 70 years for young, middle-aged and older occupants respectively and is based on the mean value of age categories from the accident sample. It can be observed that in low pulse FRB impacts, the injury risk of older drivers using the baseline SBL was almost five times greater than the younger drivers and twice as great as for middle aged drivers. A similar difference was observed in low 
pulse ODB impacts. This is seen in real world crashes where a larger proportion of older occupants sustained AIS 2+ chest injuries in low severity crashes. The chest injury risk of older drivers in the EuroNCAP impact was approximately 3.5 and 1.5 times greater than the young and middle aged drivers respectively.

\section{Real World Benefit Quantification}

Simulations showed that, providing intrusion is controlled, varying the SBL threshold can reduce chest injury without increasing risk to other body regions. Of the 377 occupants who had sustained AIS 2+ chest injury from the seat belt alone, 298 (79\%) were matched with a simulated scenario. Details of the categorisation of the matched cases (298) with the frequency of occurrence are shown in Table 4. This reduced target sample of 298 occupants consisted of 221 (74\%) drivers and 77 (26\%) front passengers. Of which 35 (12\%) occupants were young, 165 (55\%) were middle aged and 99 (33\%) were older occupants.

The potential benefit of a smart load limiter was then estimated by using Eq. (2). For those 79 cases which were not matched with a simulated scenario, it was assumed that varying the load limiter would not have produced any reduction or increase in the chest injury risk i.e. ratio of $\mathrm{R}_{\text {best }}$ and $\mathrm{R}_{\text {base }}$ is 1 . It was also assumed that all vehicles in the target sample of accident data had $4 \mathrm{kN}$ load limiters (similar to the baseline numerical model) and that the relative changes in simulated risk would also apply to the real world crashes. Table 5 illustrates the real world potential of intelligently varying the load limiter threshold. The result suggests that, if all the vehicles in the accident sample had used the best SBL setting, the proportion of older occupants who had sustained AIS $2+$ seat belt chest injury in frontal crashes would have reduced to $8.1 \%$ from the actual accident injury risk of $13.1 \%$ For young and middle aged occupants, the corresponding chest injury risk would have reduced to $0.9 \%$ and $4.9 \%$ from their actual accident injury risk of $1.3 \%$ and $7.6 \%$ respectively.

\section{DISCUSSION}

In real crashes, older people were found to sustain significantly higher rates of AIS 2+ chest injury, concurring with earlier real world studies (Morris et al. 2003; Welsh et al. 2006; Hill et al. 1994). There were also noticeable differences in the mean ETS between age groups when chest injury occurred. Older occupants tended to sustain proportionally more AIS 2+ chest injuries in low/moderate speed impacts. This is in agreement with previous studies (Augenstein et al. 2005; Welsh et al. 2006; Mertz \& Dalmotas 2007). Skeletal fracture was the most common chest injury at the AIS 2+ level and the majority of them were caused by seat belt loading. This finding clearly suggests the need to reduce restraint forces in frontal impacts with low severity crash pulses, especially for elderly vehicle occupants.

Crash simulations were developed to represent a range of real world frontal crashes with low, medium and high impact severities but with no passenger compartment intrusion. Within the simulations, the seat belt load limiter threshold (SBL) was varied away from a $4 \mathrm{kN}$ baseline and the effect on injury risk noted.

For the $50^{\text {th }}$ percentile driver with low and mid severity crash pulses, the SBL threshold set at $2 \mathrm{kN}$ and $3 \mathrm{kN}$ respectively, produced the best chest and overall injury outcomes with safe dummy displacement. In both NCAP scenarios (high pulse), the higher belt payout with the $2 \mathrm{kN}$ SBL allowed the dummy to move further toward the steering wheel. In those cases, chest deflection was still lower with the $2 \mathrm{kN}$ compared to the $4 \mathrm{kN}$ SBL but peak 
chest acceleration was increased. If the dummy had displaced only a little further, it is likely that it would have bottomed out the airbag and struck the steering wheel, resulting in increased chest injury risk. This suggests that caution is needed when choosing a driver load limiter threshold below baseline in high speed impacts. With the USNCAP pulse, the excursion of the driver dummy with the baseline $4 \mathrm{kN} \mathrm{SBL}$ was on the border of the safe zone (80mm from steering wheel). With the $6 \mathrm{kN} \mathrm{SBL}$ it was well within the safe zone but the predicted chest injury and overall injury risk was much higher compared to the baseline SBL. For this reason, the baseline SBL was chosen as the best model and illustrates the trade-off issues between load limiting to reduce occupant restraint loads and forward excursion with possible hard contact on interior structures. These findings are consistent with the load limiter adaptation studies reported in the literature (Kitagawa \& Yasuki 2013; Hynd et al. 2012) where lowering the seatbelt load limit increased chest injury caused by steering wheel contact.

Simulations with the $50^{\text {th }}$ percentile male dummy on the passenger side showed that the $2 \mathrm{kN}$ SBL models produced the best chest and overall injury scores in low severity impacts respectively. Whilst the $3 \mathrm{kN} \mathrm{SBL}$ produced the best injury protection in mid and EuroNCAP impacts with stable airbag loading. Compared to the driver, there appeared to be more scope for the use of a SBL under $4 \mathrm{kN}$ in that high pulse front passenger impact due to more available ride-down distance.

The lack of protection offered to older vehicle occupants by the restraint systems tested under current regulatory and NCAP configurations was documented through literature search and accident data analysis. When factoring in the effects of occupant age however, the calculated AIS 2+ chest injury risk in all simulated scenarios predicted a greater level of injury risk to older occupants compared to their younger counterparts. In fact, in all impacts except low pulse FRB pulse, the AIS 2+ chest injury risk for older front seating occupants with a baseline SBL was greater than 50\%. This clearly highlights the shortcomings of traditional single point restraint systems and in general the use of a non-age related injury limit in crash test procedures. In an ideal scenario, the vehicle restraints should provide equal protection to occupants of different ages and such systems would consider the effect of ageing on injury tolerance. The adaptive system studied has shown its potential to reduce the chest injury risk, particularly in crashes with a low pulse, which was the real world scenario where the number of chest injured older occupants was highest. Inclusion of a low speed impact with a lower chest injury requirement in regulatory testing could address this issue by encouraging manufacturers to adopt variable restraints. Digges and Dalmotas (Digges \& Dalmotas 2007) have already established that the addition of 40 $\mathrm{km} / \mathrm{h}$ rigid barrier tests and appropriate injury criteria levels would provide significant chest injury reduction, particularly to elderly occupants in the US. Inclusion of such tests would also have benefits in Europe, particularly because vehicle structures are generally encouraged to be "stiff" by high speed offset frontal tests. It is not clear however if great gains in driver chest protection could be achieved with a smarter load limiter in high speed, high pulse impact scenarios, where major benefits have not been found in this analysis. There may be more scope for front seat passenger protection as suggested by the simulation results for the front seat passenger in the EuroNCAP simulation.

The real world benefit of a smart load limiter was calculated by applying simulation results to the real world data sample. Simulated injury risks by occupant age and crash configuration were matched to occupant age and crash configuration in the real world impacts. In the absence of thoracic deformation detail from injured occupants, it was assumed that the predicted baseline chest injury risk from the simulations corresponded to the 
real world chest injury risk and moreover, that the relative reduction in the chest injury risk through best load limiter selection in the simulation would reduce the real world chest injury risk by a similar amount. For crashes not be matched to the simulations, it was assumed that the real world chest injury risk would remain the same. In other words, the load limiting level would not change. The results showed that if all the vehicles in the sample studied been equipped with smart load limiters able to adapt to the best setting for crash configuration and occupant type then, 36\% of the front seat occupants who had previously sustained AIS 2+ chest injury from the seat belt would have sustained a lower chest injury AIS score. Additionally, the rate of AIS 2+ seat belt chest injury in frontal crashes would have reduced to $8.1 \%$ from the actual accident rate of $13.1 \%$ for older occupants. For young and middle aged occupants, the corresponding chest injury rate would have reduced to $0.9 \%$ and $4.9 \%$ from their actual accident injury rate of $1.3 \%$ and $7.6 \%$ respectively. This finding shows a clear indication of chest injury reduction benefit across all age groups when the load limiter characteristics are varied. This suggests that employing smart restraint systems in a vehicle would not only benefit the older occupants but also the middle aged and young occupants. The benefit does appear to be most pronounced for older occupants, since the older population is more vulnerable to chest injury. As the older population of car users is rapidly rising, the benefits of smarter systems can only increase in the future.

Representing real world impacts with a limited number of simulations or crash tests always involve assumptions and compromises due to the wide variation in real world crashes. Injury outcome with real people depends on occupant age, state of health, size, seating position and seating posture. There is a large variation in crashes in terms of speed, impact angle, overlap with struck object and type of struck object. Even for the same impact configuration, the crash pulse will vary due to the particular force deflection characteristics of individual vehicles, and occupant injury outcome will vary depending on individual restraint system performance parameters. The biofidelity of ATDs and the accuracy of risk assessment functions also come into play. When matching simulations with real world impacts, we tried to consider as many variables as possible given the limited availability of simulated crash pulses and data available from real crashes. Even so, there was not a direct match between chest injury risk in baseline simulations and in equivalent real world crashes, although the order in which the predicted risk increased by simulated impact configuration was generally mirrored in the real crashes. More simulated crash configurations and more accident data would have allowed a greater tuning of simulations to real world crashes and this is recommended for future work. An injury risk function was used in this study to convert chest injury criteria from simulations into an AIS 2+ chest injury severity risk for real occupants. The function was validated based on the original real world data considered by Laituri et al. (2005). Future enhancement of the function could involve validation with more recent data and restraint conditions.

Passenger compartment intrusion was not considered in this study based on two premises. Most European vehicles would exhibit minimal intrusion in the selected impact scenarios and intrusion would limit the scope for injury reduction using variable load limiters. Further work could consider the effect of adaptable load limiters under intrusion conditions possibly complemented by variable airbag volume and deployment timing to enhance the scope for load limiting of the belt. Optimal tuning of the airbag to the load limiter characteristics could allow improved protection across a wider range of frontal crashes.

The benefit calculations in this study assumed that all vehicles in the accident sample were fitted with a baseline $4 \mathrm{kN}$ load limiter although the type of load limiter was not recorded in the accident data. Earlier load limiters 
may have been set as high as $6 \mathrm{kN}$ but simulations of the most common low pulse crashes showed minimal difference in shoulder belt loads using a $4 \mathrm{kN}$ or $6 \mathrm{kN}$ SBL. In that respect, the impact of not knowing the load limiter threshold in the real world sample is likely to be minimal.

In this study, the effect of variable seat belt load limiting on different sized occupants was not investigated. The SBL threshold selected for $50^{\text {th }}$ percentile dummy may not provide an ideal protection to other sized occupants, whose stature and adopted seat fore/aft position are generally different. Conducting simulations with dummies of different sizes $\left(5^{\text {th }}\right.$ and $\left.95^{\text {th }}\right)$ and quantifying the real world injury benefits according to the occupant size may provide a more accurate result. Additionally, the SBL threshold was varied by selected discrete values. Numerous settings could be simulated between and away from these selected values to further refine the restraint. In practise, a system capable of providing infinite load limiting thresholds, like that studied by Wang \& Zhou (2009), may provide better protection than one which can only enable set values.

\section{ACKNOWLEDGMENTS}

The authors are grateful to Mr. Tony Laituri and Mr. Scott Henry of Ford Motor Company, U.S. for their contributions in validating the AIS 2+ thoracic injury risk curves. All conclusions of the study reported in this paper are, however, solely those of the authors.

This paper uses accident data from the UK Co-operative Crash Injury Study (CCIS). CCIS was managed by TRL Limited on behalf of the UK Department for Transport (DfT) Transport Technology and Standards Division who funded the project along with Autoliv, Ford Motor Company, Nissan Motor Company and Toyota Motor Europe. Daimler-Chrysler, LAB, Rover Group Ltd, Visteon, Volvo Car Corporation, Daewoo Motor Company Ltd and Honda R\&D Europe (UK) Ltd have also funded CCIS. The data were collected by teams from the Birmingham Automotive Safety Centre of the University of Birmingham, the Vehicle Safety Research Centre at Loughborough University, TRL Limited and the Vehicle \& Operator Services Agency of the DfT. For further information about the UK collision investigation data, please go to RAIDS@dft.gsi.gov.uk 


\section{REFERENCES}

Abbreviated Injury Scale 1990 Revision. Association for the Advancement of Automotive Medicine (AAAM). 1990

Augenstein J, Digges K, Bahouth G, Dalmotas D, Perdeck E, Stratton J. Investigation of the performance of safety systems for protection of the elderly. Investigation of the performance of safety systems for protection of the elderly. Annual Proceedings / Association for the Advancement of Automotive Medicine. 2005;49, 361-369.

Bosch-Rekveldt M, Brandse J, Couper G, Morris R, Neale M. Development and application of generic restraint numerical models for parametric investigations of selected impact scenarios. Prism. Tech. Rep, 6. 2005; R7. http://www.prismproject.com/FINAL_R6-R7_PRISM_REPORT_09DEC05.PDF

Cowin S. Bone Mechanics Handbook. CRC Press; New York, NY. 2001

Department for Transport (DfT). Reported Road Casualties Great Britain: 2013 Annual Report. 2014.

Digges K, Dalmotas D. Benefits of a Low Severity Frontal Crash Test. Annual Proceedings / Association for the Advancement of Automotive Medicine. 2007;51: 299-317.

Foret-Bruno J, Hartemann F, Thomas C, Fayon A, Tarriere C, Got C, Patel A. Correlation Between Thoracic Lesions and Force Values Measured at the Shoulder of 92 Belted Occupants Involved in Real Accidents, SAE Technical Paper.1978; 780892.

Frampton R, Lenard J. The Potential for Further Development of Passive Safety.Annals of Advances in Automotive Medicine / Annual Scientific Conference. 2009;53:51-60.

Gayzik F, Yu M, Danelson K, Slice D, Stitzel J. Quantification of age-related shape change of the human rib cage through geometric morphometrics. J. Biomech. 2008;41(7):1545-1554.

Hassan A, Hill J, Parkin S. Secondary Safety Developments: Some Applications of Field Data. In: Autotech 1995; ImechE.; 1995.

Hill J, Mackay G, Morris A. Chest and abdominal injuries caused by seat belt loading. Accident Analysis Prevention. 1994;26:11-26.

Hynd D, Carroll J, Cuerden R, Kruse D, Boström O. Restraint system safety diversity in frontal impact accidents. In Proceedings of the International Research Council on the Biomechanics of Injury conference. 2012;Vol. 40, pp. 114-129.

Kent R, Trowbridge M, Lopez-Valdes FJ, Ordoyo RH, Segui-Gomez M. How Many People Are Injured and Killed as a Result of Aging? Frailty, Fragility, and the Elderly Risk-Exposure Tradeoff Assessed via a 
Risk Saturation Model. Annals of Advances in Automotive Medicine / Annual Scientific Conference. 2009;53:41-50.

Kent R, Lee S, Darvish K., Wang S, Poster CS, Lange AW, Brede C, Lange D, Matsuoka F. Structural and material changes in the aging thorax and their role in crash protection for older occupants. Stapp car crash journal. 2005; 49, 231-249.

Kent R, Henary B, Matsuoka F. On the fatal crash experience of older drivers. Proc of the Association for the Advancement of Automotive Medicine.2005;49:371-391.

Kent R, Woods W, Bostrom O. Fatality Risk and the Presence of Rib Fractures.Annals of Advances in Automotive Medicine / Annual Scientific Conference. 2008;52:73-84.

Kitagawa Y, Yasuki T. Correlation among Seatbelt Load, Chest Deflection, Rib Fracture and Internal Organ Strain in Frontal Collisions with Human Body Finite Element Models. In Proceedings of the International Research Council on the Biomechanics of Injury conference. 2013.; 2013:282-316.

Laituri T, Kachnowski B, Prasad P, Sullivan K., Przybylo P. A theoretical, risk assessment procedure for inposition drivers involved in full-engagement frontal impacts. SAE Technical Paper. 2003; 2003-01-1354

Laituri T, Prasad P, Sullivan K, Frankstein M. Thomas R. Derivation and Evaluation of a Provisional, AgeDependent, AIS3+ Thoracic Risk Curve for Belted Adults in Frontal Impacts, SAE Technical Paper.2005; 2005-01-0297.

Lanzieri G. The greying of the baby boomers. Eurostat Statistics in focus, 2011.

Lenard J, Hurley B, Thomas P. The accuracy of CRASH3 for calculating collision severity in Modern European Cars. The $16^{\text {th }}$ International Conference on the Enhanced Safety of Vehicles Conference (ESV) 1998;Windosr.

Mackay G, Ashton S, Galer M, Thomas P. The methodology of in-depth studies of car crashes in Britain . SAE Technical Paper. 1985; 850556.

Mertz H and Dalmotas D. Effects of shoulder belt limit forces on adult thoracic protection in frontal collisions. Stapp car crash journal 51 (2007): 361-380.

Morris A, Welsh R, Hassan A. Requirements for the Crash Protection of Older Vehicle Passengers. Annual Proceedings / Association for the Advancement of Automotive Medicine. 2003;47:165-180.

Nakahira Y, Furukawa K, Niimi H, Ishihara T, Miki K, Matsuoka F. A combined evaluation method and a modified maximum likelihood method for injury risk curves. In Proceedings of the International Research Council on the Biomechanics of Injury conference. 2000; pp. 20-22 
National Highway Traffic Safety Administration (NHTSA). Consumer Information; New Car Assessment Programme (NCAP). Washington, DC: National Highway Traffic Safety Administration, US Department of Transportation; 2008.Docket No. NHTSA-2006-26555

Richards D, Edwards M, Cookson R. Technical assistance and economic analysis in the field of legislation pertinent to the issue of automotive safety: provision of information and services on. Final Rep.2010. CPR815 ENTR/05/17.01,

TNO. MADYMO Applications manual version 7.4. 1.Delft, Netherlands; 2013.

Viano D. Evaluation of biomechanical response and potential injury from thoracic impact. Symposium on Biodynamic Models and their Applications, Aviation, space, and environmental medicine.1977; 49, Number 1, Section II, January 1978.

Wang C, Zhou Q. Concept study of adaptive seatbelt load limiter using magnetorheological fluid. The $21^{\text {st }}$ International Technical Conference on the Enhanced Safety of Vehicles Conference (ESV). 2009.

Welsh R, Morris A, Hassan A, Charlton J. Crash characteristics and injury outcomes for older passenger car occupants. Transportation research part F: traffic psychology and behaviour. 2006;9:322-334.

World Health Organization. WHO global status report on road safety 2013: supporting a decade of action. World Health Organization. 2013. 
Figures and Tables

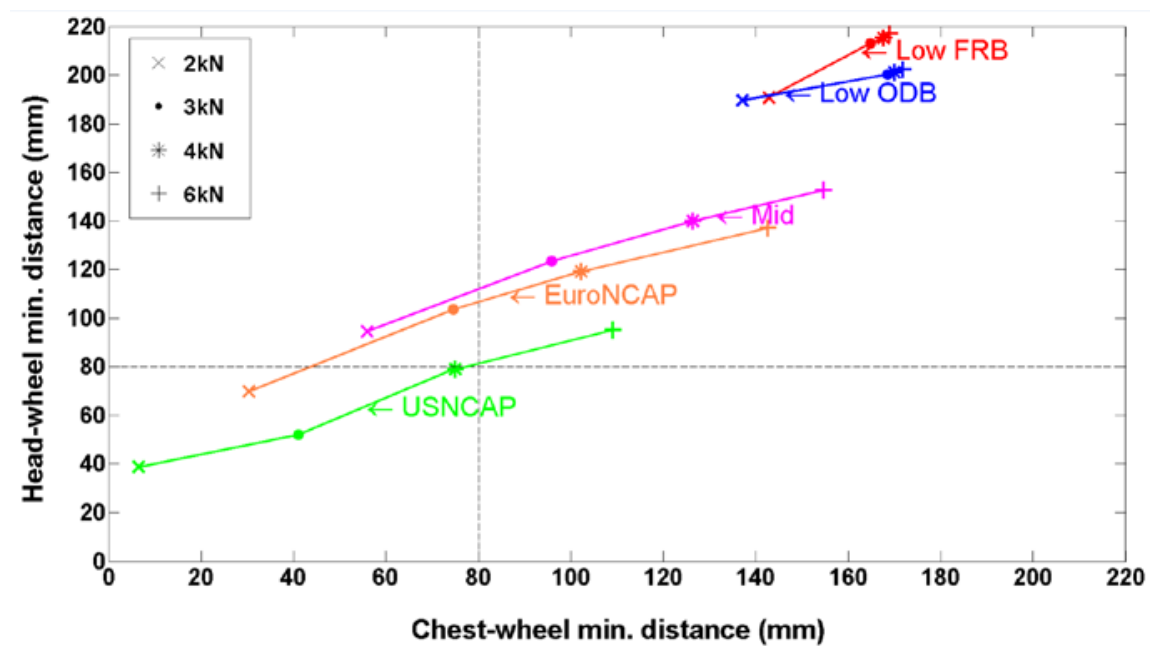

Figure 1 Head and chest to steering wheel minimum distance for driver simulations

Table 1 Driver model 2 and $4 \mathrm{kN}$ simulation results

\begin{tabular}{|c|c|c|c|c|c|c|c|c|c|c|}
\hline Injury Predictions & \multicolumn{2}{|c|}{ Low FRB } & \multicolumn{2}{|c|}{ Low ODB } & \multicolumn{2}{|c|}{ Mid } & \multicolumn{2}{c|}{ EuroNCAP } & \multicolumn{2}{c|}{ USNCAP } \\
\cline { 2 - 11 } & $\mathbf{2 ~ k N}$ & $\mathbf{4 ~ k N}$ & $\mathbf{2 ~ k N}$ & $\mathbf{4 ~ k N}$ & $\mathbf{2 ~ k N}$ & $\mathbf{4 ~ k N}$ & $\mathbf{2 ~ k N}$ & $\mathbf{4 ~ k N}$ & $\mathbf{2 ~ k N}$ & $\mathbf{4 ~ k N}$ \\
\hline Head peak Acc. (g) & 44.3 & 47.7 & 39.2 & 42.2 & 51.0 & 58.5 & 59.7 & 60.5 & 80.8 & 85.1 \\
\hline HIC $_{15}$ & 97 & 137 & 104 & 130 & 238 & 291 & 343 & 372 & 713 & 781 \\
\hline Neck Extn. (Nm) & 8.1 & 8.8 & 8.8 & 7.2 & 19.7 & 7.8 & 27.6 & 11.8 & 12.6 & 14.8 \\
\hline Nij & 0.19 & 0.2 & 0.18 & 0.18 & 0.23 & 0.27 & 0.28 & 0.27 & 0.36 & 0.26 \\
\hline Chest Peak Acc. (g) & 20.3 & 22.9 & 19.3 & 19.7 & 35.2 & 34.7 & 42.2 & 40.9 & 51.6 & 50.5 \\
\hline Chest Comp. (mm) & 22.9 & 28.4 & 23.1 & 29.5 & 26.1 & 34.2 & 28.3 & 35.8 & 28.0 & 35.2 \\
\hline Femur force (kN) & 1.7 & 0.7 & 1.0 & 0.4 & 2.2 & 2.1 & 2.3 & 2.2 & 2.9 & 2.6 \\
\hline Pjoint (\%) & 7.6 & 8.7 & 7.5 & 8.9 & 9.2 & 13.0 & 11.4 & 15.0 & 21.7 & 25.3 \\
\hline
\end{tabular}

Table 2 Passenger model 2 and 4 kN simulation results

\begin{tabular}{|c|c|c|c|c|c|c|c|c|c|c|}
\hline \multirow{2}{*}{ Injury Predictions } & \multicolumn{2}{|c|}{ Low FRB } & \multicolumn{2}{|c|}{ Low ODB } & \multicolumn{2}{|c|}{ Mid } & \multicolumn{2}{c|}{ EuroNCAP } & \multicolumn{2}{c|}{ USNCAP } \\
\cline { 2 - 11 } & $\mathbf{2 ~ k N}$ & $\mathbf{4 ~ k N}$ & $\mathbf{2 ~ k N}$ & $\mathbf{4 ~ k N}$ & $\mathbf{2 ~ k N}$ & $\mathbf{4 ~ k N}$ & $\mathbf{2 ~ k N}$ & $\mathbf{4 ~ k N}$ & $\mathbf{2 ~ k N}$ & $\mathbf{4 ~ k N}$ \\
\hline Head peak Acc. (g) & 26.6 & 28.0 & 18.7 & 23.9 & 46.8 & 44.4 & 55.9 & 53.0 & 91.0 & 91.3 \\
\hline HIC $_{15}$ & 41 & 35 & 18 & 38 & 170 & 180 & 255 & 375 & 704 & 844 \\
\hline Neck Extn. (Nm) & 8.1 & 8.3 & 6.9 & 7.1 & 7.1 & 7.2 & 7.5 & 7.7 & 12.3 & 15.2 \\
\hline Nij & 0.19 & 0.16 & 0.15 & 0.19 & 0.24 & 0.25 & 0.26 & 0.28 & 0.28 & 0.35 \\
\hline Chest Peak Acc. (g) & 20.0 & 22.3 & 16.7 & 18.4 & 32.3 & 32.5 & 40.0 & 38.7 & 48.5 & 48.3 \\
\hline Chest Comp. (mm) & 21.5 & 25.8 & 19.0 & 29.2 & 23.8 & 30.9 & 25.6 & 32.8 & 28.5 & 37.2 \\
\hline Femur force (kN) & 1.7 & 0.9 & 0.5 & 0.3 & 2.0 & 1.3 & 2.1 & 1.7 & 3.1 & 2.9 \\
\hline Pjoint (\%) & 7.3 & 7.7 & 6.3 & 8.8 & 8.4 & 10.4 & 9.5 & 13.3 & 20.8 & 29.5 \\
\hline
\end{tabular}


Table 3 Estimated chest injury risk of baseline and best SBL models

\begin{tabular}{|c|c|c|c|c|c|c|c|c|c|}
\hline \multirow[t]{2}{*}{$\begin{array}{l}\text { Seating } \\
\text { Position }\end{array}$} & \multirow[t]{2}{*}{$\begin{array}{c}\text { Crash } \\
\text { Scenario }\end{array}$} & \multicolumn{2}{|c|}{ Best SBL } & \multicolumn{3}{|c|}{$\begin{array}{c}\text { Baseline AIS 2+ risk } \\
\left.\text { [R } \mathrm{R}_{\text {base }}\right](\%)\end{array}$} & \multicolumn{3}{|c|}{$\begin{array}{c}\text { Best AIS 2+ risk } \\
{\left[\mathrm{R}_{\text {best }}\right](\%)}\end{array}$} \\
\hline & & $\begin{array}{l}\text { SBL } \\
(\mathbf{k N})\end{array}$ & $\begin{array}{c}\mathrm{CC} \\
(\mathrm{mm})\end{array}$ & Young & Mid & Old & Young & Mid & Old \\
\hline \multirow[t]{5}{*}{ Driver } & Low FRB & 2 & 22.9 & 8.7 & 22.9 & 47.9 & 4.1 & 11.8 & 29.4 \\
\hline & Low ODB & 2 & 23.1 & 10.0 & 25.6 & 51.6 & 4.3 & 12.1 & 30.0 \\
\hline & Mid & 3 & 30.0 & 16.9 & 38.6 & 66.1 & 10.6 & 26.9 & 53.3 \\
\hline & EuroNCAP & 4 & 35.8 & 20.2 & 43.9 & 70.8 & 20.2 & 43.9 & 70.8 \\
\hline & USNCAP & 4 & 35.2 & 18.6 & 41.5 & 68.8 & 18.6 & 41.5 & 68.8 \\
\hline \multirow[t]{5}{*}{ FSP } & Low FRB & 2 & 21.5 & 6.2 & 17.1 & 39.0 & 3.4 & 9.7 & 25.0 \\
\hline & Low ODB & 2 & 19.0 & 9.6 & 24.8 & 50.6 & 2.3 & 6.7 & 18.2 \\
\hline & Mid & 3 & 26.8 & 11.8 & 29.3 & 56.2 & 7.1 & 19.2 & 42.4 \\
\hline & EuroNCAP & 3 & 28.3 & 14.5 & 34.5 & 62.1 & 8.6 & 22.6 & 47.5 \\
\hline & USNCAP & 4 & 37.2 & 22.6 & 47.4 & 73.7 & 22.6 & 47.4 & 73.7 \\
\hline
\end{tabular}

Table 4 Accident sample categorisation details of AIS 2+ seat belt chest injured occupants

\begin{tabular}{|c|c|c|}
\hline Simulated scenarios & Real Crashes & $\begin{array}{c}\text { Matched } \\
\text { sample (N) }\end{array}$ \\
\hline $26 \mathrm{~km} / \mathrm{h} 100 \%$ & ETS $\leq 40 \mathrm{~km} / \mathrm{h}$ full overlap & 155 \\
\hline $40 \mathrm{~km} / \mathrm{h} 40 \%$ & ETS $\leq 45 \mathrm{~km} / \mathrm{h}$ offset & 116 \\
\hline $56 \mathrm{~km} / \mathrm{h} 40 \%$ & ETS $46-60 \mathrm{~km} / \mathrm{h}$ offset & 2 \\
\hline $64 \mathrm{~km} / \mathrm{h} 40 \%$ & $61-70 \mathrm{~km} / \mathrm{h}$ offset & 0 \\
\hline $56 \mathrm{~km} / \mathrm{h} 100 \%$ & $41-70 \mathrm{~km} / \mathrm{h}$ full overlap & 25 \\
\hline No simulation & Unmatched crashes & 377 \\
\hline
\end{tabular}


Table 5 Estimated injury risk of smart restraint system (95\% CI)

\begin{tabular}{|c|c|c|c|c|c|}
\hline $\begin{array}{c}\text { Age } \\
\text { group }\end{array}$ & $\begin{array}{l}\text { Total No. of } \\
\text { Occupants } \\
\text { (A1) }\end{array}$ & $\begin{array}{l}\text { AIS 2+ seat } \\
\text { belt chest } \\
\text { injured } \\
\text { (A2) }\end{array}$ & $\begin{array}{c}\text { Actual risk } \\
\text { (A2/A1) } \\
(\%)\end{array}$ & $\begin{array}{l}\text { Estimated No. of } \\
\text { AIS 2+ seat belt } \\
\text { chest injured } \\
\text { (A3) }\end{array}$ & $\begin{array}{c}\text { Estimated risk } \\
\text { (A3/A1) } \\
\text { (\%) }\end{array}$ \\
\hline Young & 4108 & 52 & $\begin{array}{c}1.3 \\
(0.9-1.6)\end{array}$ & 37 & $\begin{array}{c}0.9 \\
(0.6-1.2)\end{array}$ \\
\hline Mid & 2713 & 206 & $\begin{array}{c}7.6 \\
(6.6-8.6)\end{array}$ & 132 & $\begin{array}{c}4.9 \\
(4.0-5.7)\end{array}$ \\
\hline Old & 908 & 119 & $\begin{array}{c}13.1 \\
(10.9-15.3)\end{array}$ & 74 & $\begin{array}{c}8.1 \\
(6.3-9.9)\end{array}$ \\
\hline Total & 7729 & 377 & $\begin{array}{c}4.9 \\
(4.4-5.4)\end{array}$ & 243 & $\begin{array}{c}3.1 \\
(2.7-3.5)\end{array}$ \\
\hline
\end{tabular}


APPENDIX 1:
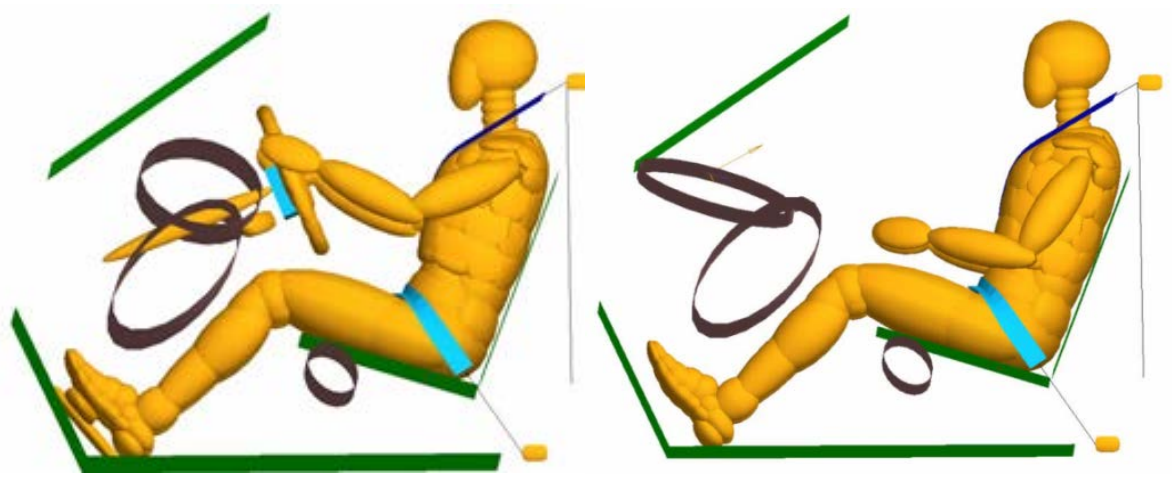

Figure A 1Baseline driver (left) and front passenger (right) simulation models 
APPENDIX 2:

Table A 1Attributes of the selected real world car sample from the NHTSA frontal crash test reports

\begin{tabular}{|c|c|c|c|c|c|c|c|c|c|c|}
\hline S.No. & $\begin{array}{l}\text { Make } \\
\text { and } \\
\text { Model }\end{array}$ & Year & $\begin{array}{l}\text { Vehicle } \\
\text { type }\end{array}$ & $\begin{array}{l}\text { Steering } \\
\text { Wheel } \\
\text { Angle } \\
\text { (deg) }\end{array}$ & $\begin{array}{l}\text { Steering } \\
\text { Column } \\
\text { Angle } \\
\text { (deg) }\end{array}$ & $\begin{array}{l}\text { Head to } \\
\text { Windshield } \\
\text { (mm) }\end{array}$ & $\begin{array}{l}\text { Nose } \\
\text { to } \\
\text { Rim } \\
(\mathrm{mm})\end{array}$ & $\begin{array}{l}\text { Chest to } \\
\text { Steering } \\
\text { Hub } \\
\text { (mm) }\end{array}$ & $\begin{array}{l}\text { Rim to } \\
\text { Abdomen } \\
(\mathrm{mm})\end{array}$ & $\begin{array}{l}\text { Pelvic } \\
\text { Angle } \\
(\mathrm{mm})\end{array}$ \\
\hline 1 & $\begin{array}{l}\text { Hyundai } \\
\text { Accent }\end{array}$ & 2010 & $\begin{array}{l}3 \text { door } \\
\text { Hatchback }\end{array}$ & 65.7 & 24.3 & 570 & 451 & 335 & 201 & 23.4 \\
\hline 2 & $\begin{array}{l}\text { Chevrolet } \\
\text { Volt }\end{array}$ & 2011 & $\begin{array}{l}5 \text { door } \\
\text { Hatchback }\end{array}$ & 68.5 & 21.5 & 803 & 426 & 347 & 239 & 24.7 \\
\hline 3 & $\begin{array}{l}\text { Ford } \\
\text { Focus }\end{array}$ & 2012 & $\begin{array}{l}5 \text { door } \\
\text { Hatchback }\end{array}$ & 67.5 & 22.5 & 775 & 401 & 349 & 209 & 24.1 \\
\hline 4 & $\begin{array}{l}\text { Nissan } \\
\text { Leaf }\end{array}$ & 2013 & $\begin{array}{l}5 \text { door } \\
\text { Hatchback }\end{array}$ & 64 & 26 & 653 & 388 & 292 & 168 & 20.3 \\
\hline 5 & $\begin{array}{l}\text { Honda } \\
\text { Insight }\end{array}$ & 2010 & $\begin{array}{l}4 \text { door } \\
\text { hatchback }\end{array}$ & 71.3 & 18.7 & 738 & 356 & 287 & 197 & 23.5 \\
\hline
\end{tabular}

Table A 2 Comparison of baseline model attributes with the real world sample.

\begin{tabular}{|c|c|c|c|c|c|}
\hline \multirow{2}{*}{ Measurement Description } & \multirow{2}{*}{ Units } & \multirow{2}{*}{ Baseline } & \multicolumn{3}{|c|}{ Real World Sample } \\
\hline & & & $25^{\text {th }}$ percentile & Mean & $75^{\text {th }}$ percentile \\
\hline Steering Wheel Angle & deg & 67.4 & 63.9 & 67.4 & 70.8 \\
\hline Steering Column Angle & deg & 22.7 & 19.1 & 22.6 & 26 \\
\hline Head to Windshield Distance & $\mathrm{mm}$ & 575 & 589 & 707 & 826 \\
\hline Nose to Rim Distance & $\mathrm{mm}$ & 415 & 359 & 404 & 449 \\
\hline Chest to Steering Hub Distance & $\mathrm{mm}$ & 320 & 294 & 322 & 332 \\
\hline Rim to Abdomen Distance & $\mathrm{mm}$ & 206 & 171 & 202.8 & 234 \\
\hline Pelvic Angle & deg & 22.9 & 21.1 & 23.2 & 25.3 \\
\hline
\end{tabular}


APPENDIX 3:

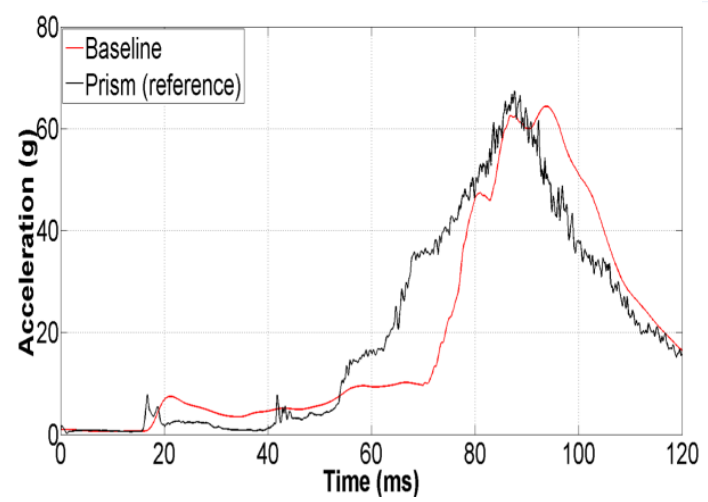

Driver head

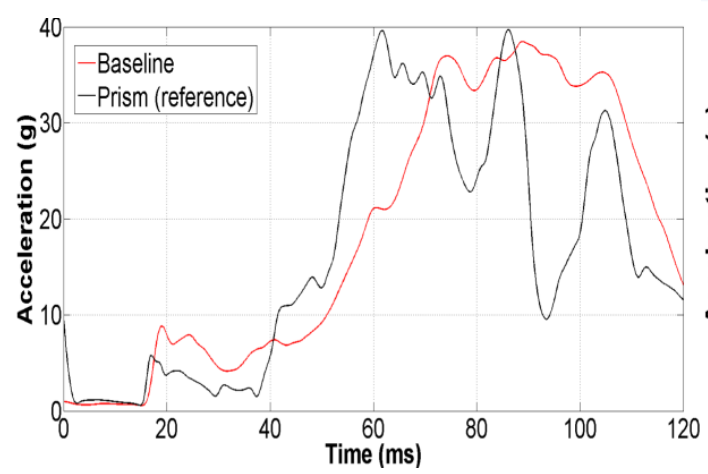

Driver chest

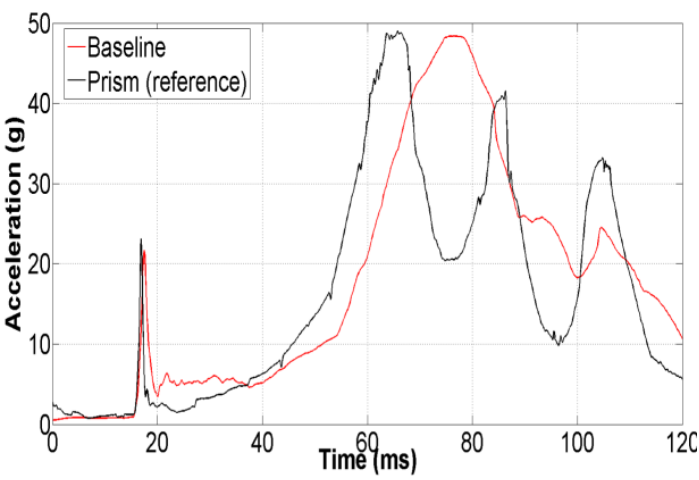

Driver pelvis

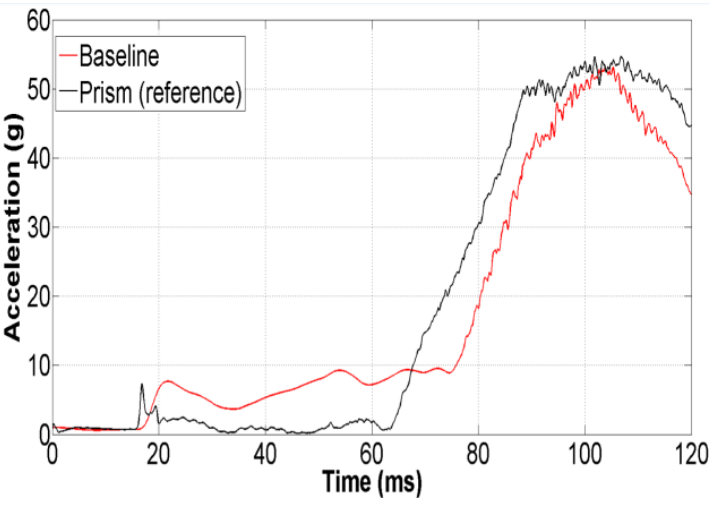

Passenger head

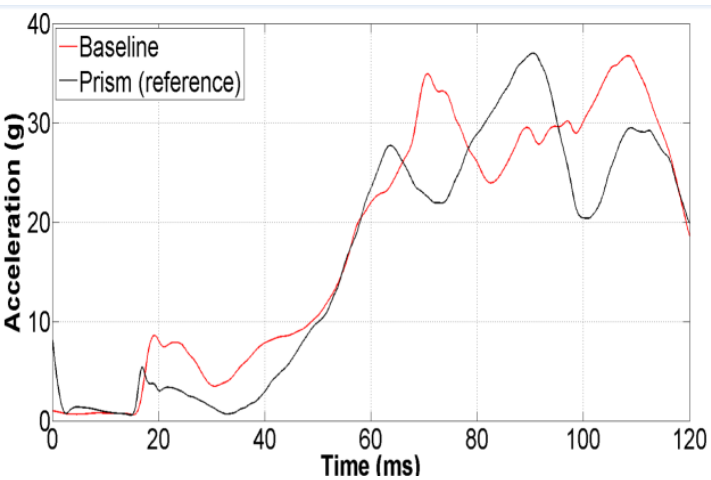

Passenger chest

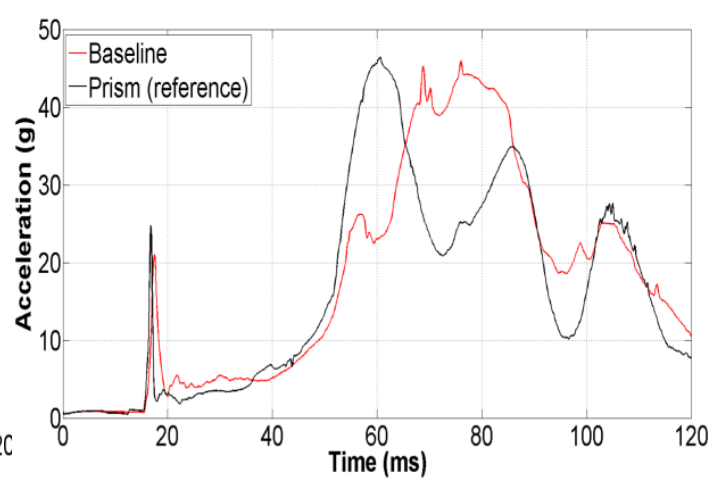

Passenger pelvis

Figure A2 Comparison of predicted head, chest and pelvis acceleration for current baseline study compared to Prism reference models with EuroNCAP impact pulse 
Table A 3 Comparison of chest compression measurements (CC) and peak acceleration between baseline and reference models using a EuroNCAP impact pulse.

\begin{tabular}{lll}
\hline \multirow{2}{*}{ Model } & \multicolumn{1}{l}{ Driver } & Passenger \\
\cline { 2 - 3 } & CC $(\mathbf{m m})$ & CC $(\mathbf{m m})$ \\
\hline $\begin{array}{l}\text { PRISM } \\
\text { (reference) }\end{array}$ & 29.0 & 31.2 \\
Baseline & 35.8 & 32.8 \\
\hline
\end{tabular}


APPENDIX 4:

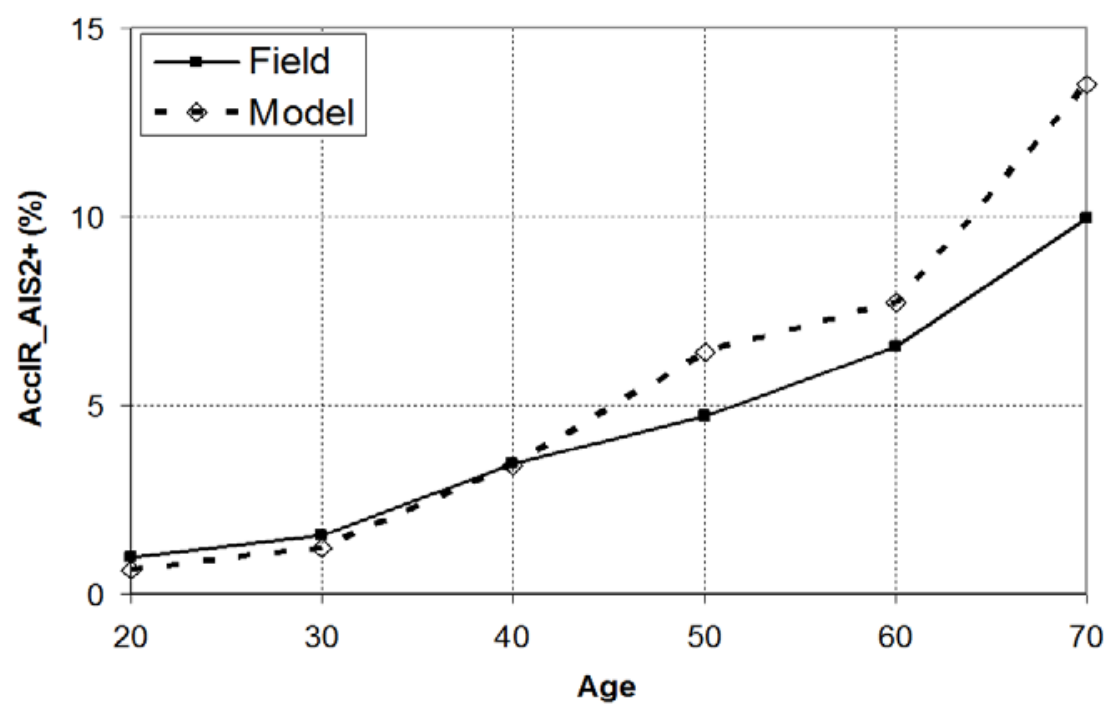

Figure A 3 Comparison of predicted accident injury rate (AccIR) from estimated injury risk function and actual accident injury rate from field data 


\section{APPENDIX 5:}

Table A 4 Predicted AIS 2+ chest injury risk versus AIS 2+ belt related chest injury risk for belted drivers in real frontal crashes

\begin{tabular}{|c|c|c|c|}
\hline $\begin{array}{l}\text { Simulated Impact } \\
\text { types (speed and } \\
\text { overlap) }\end{array}$ & $\begin{array}{l}\text { 2+ risk chest } \\
\text { deflection }\end{array}$ & $\begin{array}{c}2+\text { risk accident } \\
\text { data }\end{array}$ & $\begin{array}{c}\text { Real crash impact type } \\
\text { (speed range and overlap) } \\
(\mathrm{N})^{*}\end{array}$ \\
\hline 26 km/h 100\% & $11 \%$ & $6 \%$ & $\begin{array}{c}20-30 \mathrm{~km} / \mathrm{h}>70 \% \\
(1156)\end{array}$ \\
\hline $40 \mathrm{~km} / \mathrm{h} \quad 40 \%$ & $13 \%$ & $8 \%$ & $\begin{array}{c}35-45 \mathrm{~km} / \mathrm{h}<60 \% \\
(380)\end{array}$ \\
\hline $56 \mathrm{~km} / \mathrm{h} \quad 40 \%$ & $21 \%$ & $12 \%$ & $\begin{array}{c}51-60 \mathrm{~km} / \mathrm{h}<60 \% \\
(20)\end{array}$ \\
\hline 64 km/h $40 \%$ & $26 \%$ & $0 \%$ & $\begin{array}{c}61-70 \mathrm{~km} / \mathrm{h}<60 \% \\
\text { (3) }\end{array}$ \\
\hline 56 km/h 100\% & $24 \%$ & $20 \%$ & $\begin{array}{c}51-61 \mathrm{~km} / \mathrm{h}>70 \% \\
(46)\end{array}$ \\
\hline
\end{tabular}

$\mathrm{N}^{*}$ indicates the total number of cases in each real crash configuration 
APPENDIX 6:

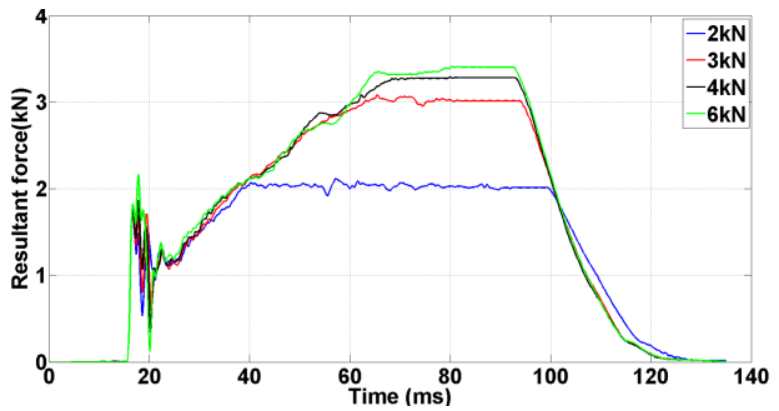

a) Low FRB

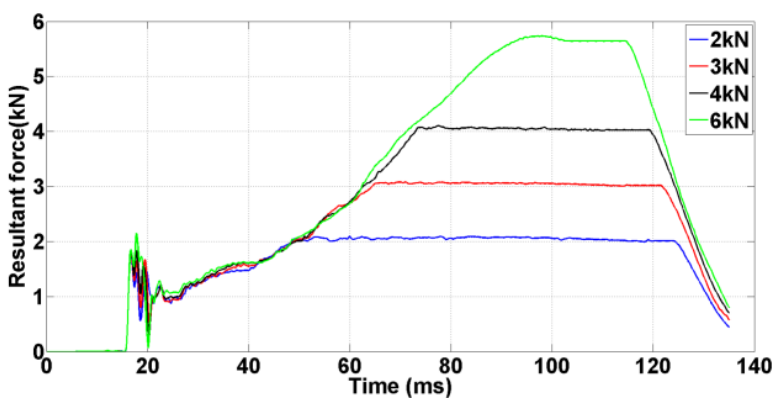

c) Mid

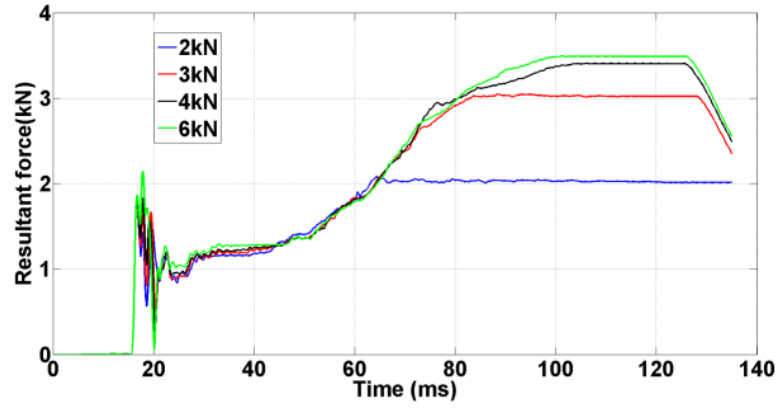

b) Low ODB

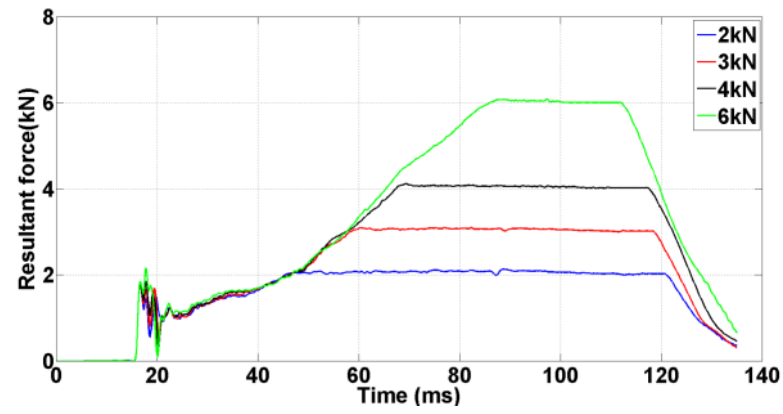

d) EuroNCAP

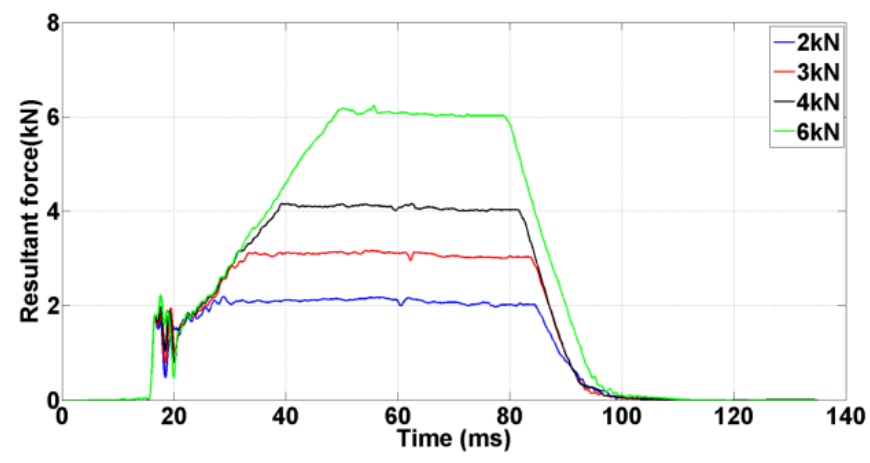

e) USNCAP

Figure A 4 Retractor belt force of $50^{\text {th }}$ Hybrid III driver 
APPENDIX 7:

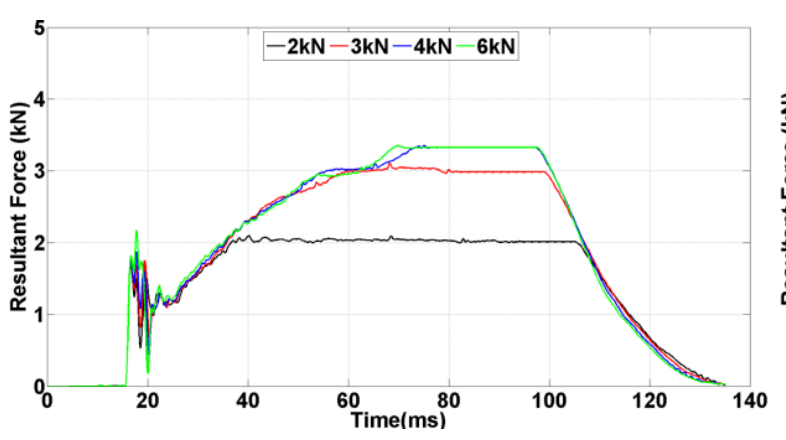

a) Low FRB

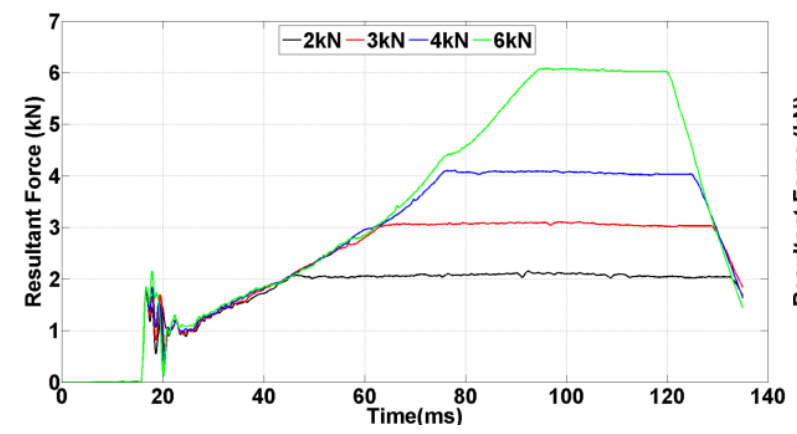

c) Mid

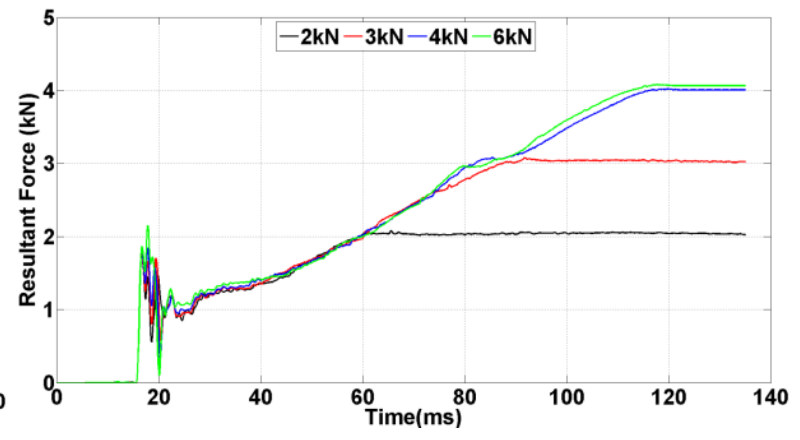

b) Low ODB

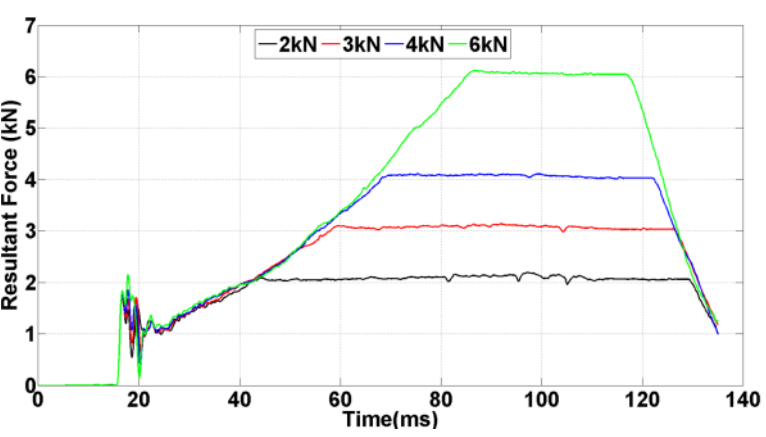

d) EuroNCAP

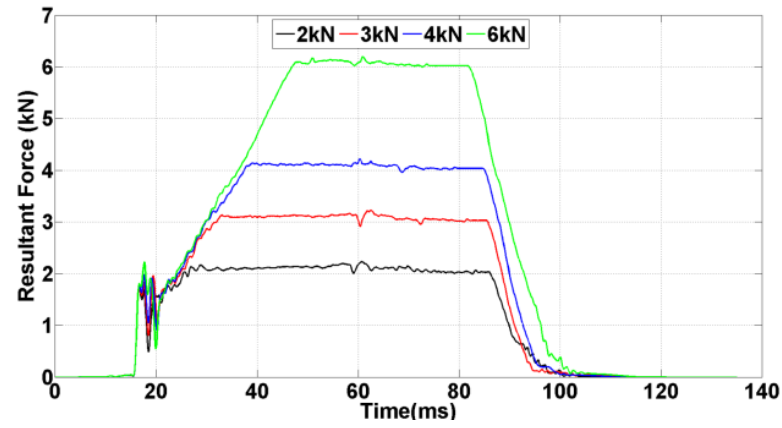

f) USNCAP

Figure A 5 Retractor belt force of $50^{\text {th }}$ Hybrid III front passenger 
APPENDIX 8:

Table A 5 Driver model simulation results

\begin{tabular}{|c|c|c|c|c|c|c|c|c|c|c|c|c|c|c|c|c|c|c|c|c|}
\hline \multirow{2}{*}{ Injury Predictions } & \multicolumn{4}{|c|}{ Low FRB } & \multicolumn{4}{|c|}{ Low ODB } & \multicolumn{4}{|c|}{ Mid } & \multicolumn{4}{|c|}{ EuroNCAP } & \multicolumn{4}{|c|}{ USNCAP } \\
\hline & $2 \mathbf{k N}$ & $3 \mathbf{k N}$ & $4 \mathbf{k N}$ & 6kN & $2 \mathrm{kN}$ & $3 \mathbf{k N}$ & $4 \mathbf{k N}$ & $6 \mathrm{kN}$ & $2 \mathbf{k N}$ & $3 \mathbf{k N}$ & $4 \mathbf{k N}$ & $\overline{\mathbf{k N}}$ & $2 \mathbf{k N}$ & $3 \mathbf{k N}$ & $4 \mathbf{k N}$ & $6 \mathrm{kN}$ & $2 \mathbf{k N}$ & $3 \mathbf{k N}$ & $4 \mathbf{k N}$ & $6 \mathrm{kN}$ \\
\hline Head peak A & 44.3 & 46.4 & 47.7 & 49.3 & 39.2 & 41.2 & 42.2 & 42.2 & 51.0 & 52.4 & 58.5 & 64.9 & 59.7 & $\begin{array}{ll}62.7 \\
\end{array}$ & 60.5 & 70.7 & 80.8 & 83 & 85.1 & 86.7 \\
\hline $\mathrm{HIC}_{15}$ & 97 & 126 & 137 & 138 & 104 & 124 & 130 & 132 & 238 & 254 & 291 & 390 & 343 & 370 & 372 & 493 & 713 & 711 & 781 & 780 \\
\hline Neck Extn. (Nm) & 8.1 & 8.5 & 8.8 & 9.1 & 8.8 & 7.1 & 7.2 & 7.5 & 19.7 & 9.4 & 7.8 & 7.7 & 27.6 & 16.1 & 11.8 & 8.3 & 12.6 & 14.6 & 14.8 & 16.0 \\
\hline $\mathrm{Ni}$ & 19 & 0.20 & 0.19 & 0.18 & 0.18 & 8 & 0.18 & 8 & 0.23 & 24 & 0.27 & 28 & 0.28 & 25 & 27 & 0.30 & .36 & 26 & .26 & .30 \\
\hline Chest Peak A & 20.3 & 22.6 & 22.9 & 22.2 & 19.3 & 19.3 & 19.7 & 19.2 & 35.2 & 34.6 & 34.7 & 38.8 & 42.2 & 41.0 & 40.9 & 43.1 & 51.6 & 50.7 & 50.5 & 56.3 \\
\hline Chest Comp. (mm) & 22.9 & 27.5 & 28.4 & 28.1 & 23.1 & 28.2 & 29.5 & 29.8 & 26.1 & 30.0 & 34.2 & 43.4 & 28.3 & 32.5 & 35.8 & 47.3 & 28.0 & 30.4 & 35.2 & 45.6 \\
\hline Femur force $(\mathrm{kN})$ & 1.7 & 0.9 & 0.7 & 0.7 & 1.0 & $\overline{0.6}$ & 0.4 & 0.3 & 2.2 & 2.0 & 2.1 & 2.0 & 2.3 & 2.0 & 2.2 & 2.2 & 2.9 & 2.8 & 2.6 & 2.5 \\
\hline Pjoint (\%) & 7.6 & 8.5 & 8.7 & 0.5 & 7.5 & 8.5 & 8.9 & 9.0 & 9.2 & 10.5 & 13.0 & 21.0 & 11.4 & 12.9 & 15.0 & 27.2 & 21.7 & 21.2 & 25.3 & 32.9 \\
\hline
\end{tabular}

Table A 6 Passenger model simulation results

\begin{tabular}{|c|c|c|c|c|c|c|c|c|c|c|c|c|c|c|c|c|c|c|c|c|}
\hline \multirow{2}{*}{ Injury Predictions } & \multicolumn{4}{|c|}{ Low FRB } & \multicolumn{4}{|c|}{ Low ODB } & \multicolumn{4}{|c|}{ Mid } & \multicolumn{4}{|c|}{ EuroNCAP } & \multicolumn{4}{|c|}{ USNCAP } \\
\hline & $2 \mathrm{kN}$ & $3 \mathbf{k N}$ & $4 \mathbf{k N}$ & $6 \mathrm{kN}$ & $2 \mathbf{k N}$ & $3 \mathbf{k N}$ & $4 \mathbf{k N}$ & $6 \mathrm{kN}$ & $2 \mathbf{k N}$ & $3 \mathbf{k N}$ & $4 \mathbf{k N}$ & $\mathbf{k N}$ & $2 \mathbf{k N}$ & $3 \mathbf{k N}$ & $4 \mathbf{k N}$ & $6 \mathrm{kN}$ & $\mathbf{k N}$ & $3 \mathbf{k N}$ & $4 \mathbf{k N}$ & $6 \mathrm{kN}$ \\
\hline Hea & 5.6 & 3.7 & 28.0 & 27.9 & 18.7 & 21.2 & 3.9 & 24.3 & 46.8 & 44.0 & 44.4 & 55.7 & 55.9 & 52.9 & 53.0 & 61.0 & 91.0 & \begin{tabular}{|l|}
95.8 \\
\end{tabular} & 1.3 & 91.7 \\
\hline $\mathrm{HIC}_{15}$ & 41 & 34 & 35 & 38 & 18 & 27 & 38 & 39 & 170 & 156 & 180 & 298 & 255 & 43 & 375 & 377 & 704 & 816 & 344 & 378 \\
\hline Neck Extn. & 0.1 & 0.2 & 0.5 & 0.7 & 0.9 & 0.7 & 1.1 & 7.4 & 7.1 & 7.1 & 7.2 & 1.0 & 7.5 & 7.6 & 7.7 & 8.0 & 12.3 & 13.0 & $\overline{5.2}$ & 13.1 \\
\hline $\mathrm{Nij}$ & $\overline{19}$ & 0.17 & 0.16 & 0.16 & 0.15 & 0.17 & 0.19 & 0.20 & 0.24 & 0.24 & 0.25 & 0.30 & 0.26 & 0.27 & 0.28 & 0.31 & 0.28 & 0.32 & .35 & 0.39 \\
\hline Chest Peak Acc. (g) & 20.0 & 22.0 & 22.3 & 22.6 & 16.7 & 18.1 & 18.4 & 18.5 & 32.3 & 30.2 & 32.5 & 34.0 & 40.0 & 38.7 & 38.7 & 39.9 & 48.5 & 48.8 & 48.3 & 53.3 \\
\hline Chest Comp. (mm) & 21.5 & 24.4 & 25.8 & 26.8 & 19.0 & 24.9 & 29.2 & 29.7 & 23.8 & 26.8 & 30.9 & 41.7 & 25.6 & 28.3 & 32.8 & 42.9 & 28.5 & 33.0 & 37.2 & 49.0 \\
\hline Femur force $(\mathrm{kN})$ & 1.7 & 1.0 & 0.9 & 0.9 & 0.5 & 0.4 & 0.3 & 0.3 & 2.0 & 1.3 & 1.3 & 1.2 & 2.1 & 1.8 & 1.7 & 1.6 & 3.1 & 3.1 & 2.9 & 2.7 \\
\hline Pjoint (\%) & 7.3 & 7.4 & 7.7 & 7.9 & 6.3 & 7.4 & 8.8 & 9.0 & 8.4 & 8.9 & 10.4 & 18.3 & 9.5 & 10.1 & 13.3 & 20.5 & 20.8 & 26.4 & 29.5 & 40.4 \\
\hline
\end{tabular}


